\title{
Er:YAG pre-treatment for bonding of orthodontic bracket: I year of in vitro treatment
}

Rudys Rodolfo de Jesus

Tavarez'

Gisele Lima Bezerra²

Karla Janilee de Souza

Penha $^{3}$

Carlos Rocha Gomes

Torres $^{4}$

Leily Macedo Firoozmand ${ }^{5}$

'Department of Dentistry, Ceuma University (UNICEUMA), ${ }^{2}$ Dentistry

Program, Ceuma University

(UNICEUMA), ${ }^{3}$ Dentistry Program,

Federal University of Maranhão,

UFMA, São Luís, MA, ${ }^{4}$ Restorative

Dentistry Department, ICT UNESP

University, São Paulo, ${ }^{5}$ Dentistry

Department I, Federal University of

Maranhão,UFMA, São Luís, MA, Brazil
This article was published in the following Dove Press journal:

Clinical, Cosmetic and Investigational Dentistry

27 March 2017

Number of times this article has been viewed

Objective: The aim of this study was to evaluate in vitro bond strength of metal brackets bonded with: total etch, total etch with erbium: yttrium aluminum garnet laser (Er:YAG) and self-etching adhesive systems, submitted to thermal-mechanical cycling, simulating 1 year of orthodontic treatment.

Materials and methods: For the study, 80 bovine incisors were randomly divided into 3 experimental groups ( $\mathrm{n}=16$ each): XT- acid etching + Transbond XT, XT/Er:YAG-Transbond XT associated with Er:YAG laser irradiation $(\lambda=2.94 \mu \mathrm{m}, 60 \mathrm{~mJ}, 10 \mathrm{~Hz})$ and SEP- Transbond Plus Self Etching Primer. Samples were submitted to thermal-mechanical cycling, simulating 1 year of orthodontic treatment. Afterward, the shear bond strength test was performed in a universal test machine at a speed of $0.5 \mathrm{~mm} / \mathrm{min}$. Samples were evaluated under a stereomicroscope and by scanning electron microscopy for analysis of enamel surface and adhesive remnant index. Data were analyzed using Kruskal-Wallis and Mann-Whitney (with Bonferroni correction) statistical tests. Results: Statistically significant difference was observed between the groups studied $(p<0.05)$. Groups XT and SEP showed the highest bond strength values, without statistical difference between them, while group XT/Er:YAG showed reduction in bond strength values. Higher frequency of adhesive failures between enamel and adhesive system was verified for groups $\mathrm{XT}$ and XT/Er:YAG.

Conclusion: The conventional (XT) and self-etching (SEP) adhesive systems showed mean bond strength values, similar between them, whereas the previous application of Er:YAG laser promoted the lowest bond strength values.

Keywords: dentin-bonding agents, orthodontic brackets, shear strength, enamel, YAG laser, self-etching adhesive system, orthodontic bonding

\section{Introduction}

In orthodontics, it is important to employ a suitable adhesive technique and methods that not only promote satisfactory bond strength during treatment, but also have a simplified protocol for clinical use, thereby reducing procedural errors and minimizing damage to the dental structure. ${ }^{1}$ Self-etching adhesive systems have acidic components in their composition, thus reducing the number of operative procedures and the inconvenience arising from excessive demineralization of the tooth structure, as occurs in the total acid etching technique. ${ }^{1,2}$

At present, erbium: yttrium aluminum garnet laser laser (Er:YAG) has been used in dentistry for performing cavity preparations, carious tissue removal, decontamination of cavities and tooth surface conditioning. ${ }^{3-5}$ Er:YAG laser is one of the types most used for hard dental tissue conditioning, ${ }^{5}$ because it allows the formation of rougher
Correspondence: Leily Macedo

Firoozmand

Department of Dentistry I, Federal

University of Maranhão, UFMA, Rua dos

Sabiás, n. I I QD07, Condominio Pont

Negra-apto 904- Renascença II, Cep:

65075-360 São Luís, MA, Brazil

Tel +559882150790

Email leilyfiroozmand@hotmail.com

Rudys Rodolfo De Jesus Tavarez Universidade Ceuma. Rua Josué Montello, S/N, 65.075-120. São Luiz, MA, Brazil

Tel +5598988283948

Email rudysd@uol.com.br 
surfaces. When it is used on dentin, it removes the tissue with the absence of a smear layer.

Irradiation with erbium laser promotes structural and morphological changes in dental hard tissues. ${ }^{4,6,7}$ When the tooth surface is conditioned with Er:YAG laser, a tissue becomes more resistant to acid dissolution around the bracket, ${ }^{4,7}$ and it appears to be effective for the prevention of caries during orthodontic treatment. ${ }^{8}$

Some studies ${ }^{3,5,9-11}$ have pointed out increased retention of the resinous material to enamel irradiated with Er:YAG laser. However, further studies need to be conducted in order to prove the efficacy of erbium laser for increasing the bond strength of orthodontic adhesives, since these data are controversial in the literature. ${ }^{6,7}$

A large portion of the studies has evaluated the bond strength of orthodontic brackets immediately after they have been bonded, ${ }^{1,2}$ but a long-term evaluation deserves emphasis, because once these brackets have been bonded, they have to remain in position throughout the entire orthodontic treatment. Therefore, studies evaluating accelerated artificial aging/thermal cycling have been suggested in the literature. ${ }^{12}$

Thus, while the self-etching system reduces the inconvenience of excessive demineralization of the tooth, ${ }^{1,2}$ the association of the Er:YAG laser with the conventional adhesive system should be evaluated, enamel resistance to acid dissolution after irradiation with Er:YAG is shown in the literature. ${ }^{4,8}$

In view of the questions raised, the aim of this study was to evaluate the in vitro bond strength of orthodontic brackets bonded with: total etch, total etch with previous application of Er:YAG laser and the self-etching adhesive systems after thermal-mechanical cycling, simulating 1 year of treatment. The null hypothesis tested was that there would be no statistically significant difference among the bond strength values when the adhesive systems and laser for orthodontic bracket bonding were used.

\section{Materials and methods}

\section{Selection and preparation of teeth}

The research project was approved by the ethics commission on animal experimentation of Ceuma University (Protocol No. 073/2013). The research followed the guidelines of National Council of Control of Animal Experimentation (CONCEA). The experimental procedures were performed on 48 recently extracted deciduous bovine incisors obtained from discarded jaws after slaughter of the animals. ${ }^{13}$ The teeth were extracted following the procedures of a minimum of trauma. The inclusion criteria used for selecting the teeth were tooth enamel without cracks/fractures and without previous application of chemical agents such as thymol, hydrogen peroxide, alcohol or formol. Teeth were cleaned, stored in distilled water and used. The sample size was calculated adopting $\alpha$ equal to 5\%, Kruskal-Wallis test power equal to $75 \%$. A sample size of (n) 16 elements in each group was found (PASS 11, NCSS, LLC, Kaysville, UT, USA).

The bovine teeth were sectioned at the cervical third and the roots were discarded. After this, the coronal pulp was removed with a dentin curette (Duflex Lucas No. 86, SS White, Rio de Janeiro, Brazil) and the pulp chamber was cleaned and obliterated with utility wax.

The teeth were placed in PVC tubes measuring $25 \mathrm{~mm} \times 20$ $\mathrm{mm}$ (Tigre, Joinville, Brazil) with the vestibular surface positioned at the bottom of the base, and then they were embedded in acrylic resin (VIPI, São Paulo, Brazil). The surface was abraded with water and abrasived paper of 200 , 400, 600 and 1200 grits (3M, Sumaré, Brazil) with the aid of a polishing machine (Panambra Técnica Imp. Exp. LTDA, São Paulo, Brazil), under irrigation and uniform, constant pressure in order to obtain a flat vestibular surface.

To prepare the experimental groups, the adhesive systems presented in Table 1 were used.

\section{Bracket bonding}

A total of 48 stainless steel orthodontic brackets for maxillary central incisors were used, with a mesh base of $1.5 \mathrm{~mm}$ height $\times 4.0 \mathrm{~mm}$ wide (Roth 0.022 " $\times 0.030$ " - KIRIUM Abzil Indústria e Comércio Ltda., São José do Rio Preto, Brazil). Prophylaxis of the tooth enamel on the vestibular surface of all the teeth was performed with pumice stone, without fluoride (SS White) and water for 10 seconds.

In the groups, the following adhesive systems were used: Transbond XT (XT), Transbond Plus Self Etch Primer system (SEP) and Er:YAG laser associated with the adhesive system Transbond XT (Er:YAG/XT) as specified in Table 1. In the group in which previous irradiation with Er:YAG laser (Kavo Key III, Kavo, Kirchdorf Biberach, Germany) was performed, the wavelength of $2.94 \mu \mathrm{m}$ was used with a \#2051 handpiece and spot diameter of $0.63 \mathrm{~mm}$ (Table 1 ).

For all the groups, the brackets were positioned with Transbond XT resin (3M) on the base, excess was removed and light polymerization was performed for 10 seconds on each surface of the bracket (mesial, distal, cervical and incisal). Maximum pressure was applied during bracket bonding in order to standardize the force exerted and the thickness of the resin pellicle, as soon as they were placed on the teeth. Excesses were removed with an exploratory probe 
Table I Experimental groups studied (adhesive systems/laser)

\begin{tabular}{|c|c|c|c|}
\hline Groups & Adhesive systems/composition & Commercial brand/lot/validity & Application mode \\
\hline $\mathrm{XT}$ & $\begin{array}{l}\text { Transbond XT - light cure adhesive } \\
\text { Adhesive: Triethylene-glycol- } \\
\text { dimethacrylate } \\
\text { Bis-GMA } \\
\text { Resin: Silica } \\
\text { Bis-GMA } \\
\text { n-Dimethylbenzocaine } \\
\text { Hexafluorophosphate }\end{array}$ & $\begin{array}{l}\text { 3M Unitek orthodontics products } \\
\text { South Peck Road, Monrovia, USA } \\
\text { Lot: } 1308100970 \\
\text { Validity: } 06 / 15\end{array}$ & $\begin{array}{l}37 \% \text { phosphoric acid etching - } 30 \text { seconds on } \\
\text { enamel } \\
\text { Washing for same time of application and drying } \\
\text { with jet of air } \\
\text { Active application of } 2 \text { layers of adhesive ( } 5 \text { seconds) } \\
\text { Use of short jet of air to evaporate solvent and } \\
\text { verify if there is a thin, uniform layer } \\
\text { Light polymerization for } 20 \text { seconds } \\
\text { Application of resin in light polymerization for } \\
10 \text { seconds on each surface }\end{array}$ \\
\hline SEP & $\begin{array}{l}\text { Transbond plus self-etching primer } \\
\text { Adhesive: Methacrylate ester of } \\
\text { phosphoric acid, water } \\
\text { Hydrofluoric complex }\end{array}$ & $\begin{array}{l}\text { 3M Unitek orthodontics products } \\
\text { South Peck Road, Monrovia, USA } \\
\text { Lot: } 48894 \text { Ic } \\
\text { Validity: } 03 / 14\end{array}$ & $\begin{array}{l}\text { Active application of } 2 \text { layers of adhesive ( } 5 \text { seconds) } \\
\text { Use of a brief jet of air } \\
\text { Light polymerization for } 20 \text { seconds } \\
\text { Application of resin and light polymerization on each } \\
\text { surface for } 10 \text { seconds }\end{array}$ \\
\hline XT/Er:YAG & $\begin{array}{l}\text { Er:YAG laser + Transbond XT } \\
\text { Laser parameters } 60 \mathrm{~mJ} \text { of energy, } \\
\text { frequency of } 10 \mathrm{~Hz} \text {, focal distance of } 12 \\
\mathrm{~mm} \text {, energy density } 19.24 \mathrm{~J} / \mathrm{cm}^{2}\end{array}$ & $\begin{array}{l}\text { Kavo Key Laser } \\
\text { Kavo do Brazil S.A. Ind. E Com. }\end{array}$ & $\begin{array}{l}\text { Scanning mode irradiation without superimposition } \\
\text { of points, performed by the same operator } \\
\text { Constant cooling with water } \\
\text { Posterior } \\
\text { Active application of } 2 \text { layers of adhesive (Transbond } \\
\mathrm{XT} \text { ) ( } 5 \text { seconds) } \\
\text { Use of short jet of air to evaporate solvent and } \\
\text { verify if there is a thin, uniform layer } \\
\text { Light polymerization for } 20 \text { seconds } \\
\text { Application of resin (Transbond XT) in light } \\
\text { polymerization for } 10 \text { seconds on each surface }\end{array}$ \\
\hline
\end{tabular}

Abbreviations: Er:YAG, erbium: yttrium aluminum garnet laser; SEP, transbond plus self-etching primer.

(Duflex No. 5) before polymerization. All the procedures were carried out by one single, duly trained and calibrated operator. Light polymerization of the adhesive system and resin was performed with a fast-curing cordless LED light (3M ESPE dental, Landsberg am Lech, Germany) polymerizing apparatus, with light intensity of approximately 800 $\mathrm{mW} / \mathrm{cm}^{2}$, checked with a radiometer (Gnatus, Ribeirão Preto, Brazil).

\section{Thermal-mechanical cycling}

The experimental groups were submitted to varying thermalmechanical cycles, using a fatigue simulator appliance (ER 11000, ERIOS, São Paulo, Brazil). In order to simulate 1 year of clinical treatment, 100,000 mechanical cycles and 500 thermal cycles were performed, which ranged between $5^{\circ} \mathrm{C}$ and $55^{\circ} \mathrm{C}$ (ISO 11405)..$^{14,15}$

\section{Shear bond strength test}

A Universal Test Machine (EMIC, São José dos Pinhais, Brazil) was used, with a $50 \mathrm{~kg}$ load applied parallel to the vestibular enamel surface, in the incisor-cervical direction close to the enamel/adhesive interface, at $0.5 \mathrm{~mm} / \mathrm{min}$ until fracture occurred. ${ }^{15,16}$ The force required to remove the brackets was measured in Newton $(\mathrm{N})$ and the shear strength in megapascals (MPa). The results were obtained with the aid of the computer software program (TESC) connected to the EMIC Universal Test Machine.

\section{Stereomicroscope and scanning electron microscopy (SEM) evaluation}

After the shear bond test, the samples were analyzed under a stereomicroscope lens (Kozo Optical and Electronical Instrumental, Nanjing-Jiangsu, People's Republic of China), at 20× magnification to determine the adhesive remnant index (ARI). This measurement was made in accordance with the scores that ranged from 0 to $3: 0$ - no composite resin adhered to enamel; 1 - less than half percent of composite resin on enamel; 2 - more than half percent of composite resin on enamel; and 3 - all composite resin on enamel, showing the bracket mesh impression. ${ }^{17,18}$

Afterward, the samples were prepared and submitted to analysis by SEM in order to visualize the adhesive remnant and/or the enamel condition after bracket removal. Images were captured by means of a specific software program coupled to the SEM (Inspect 550, Fei), allowing photomicrographs to be obtained. 


\section{Statistical analysis}

The data obtained were statistically analyzed by means of Kruskal-Wallis and Mann-Whitney tests with Bonferroni correction to verify differences between the studied groups, since the distribution of data was not considered normal, according to the Shapiro-Wilk test. The level of significance was established at $p<0.05$.

The ARI data, which were presented as an ordinal qualitative variable, were statistically analyzed with Kruskal-Wallis and Dunn tests. The level of significance was established at $p<0.05$.

The analyses were performed using the statistical software program Statistical Package for the Social Sciences (SPSS) statistics version 20.0 (IBM, Armonk, NY, USA).

\section{Results}

\section{Shear bond strength test}

The inferential and descriptive statistics of the bond strength of the groups are shown in Table 2.

After simulation of 1 year of treatment, it was observed that XT and SEP groups presented the highest shear bond strength values, without statistical differences between them. However XT/Er:YAG group showed a reduction in mean bond strength values (Table 2).

\section{Stereomicroscope evaluation}

The condition in which there was greatest predominance of $\mathrm{ARI}=0$ was that of group XT/Er:YAG. The score 0 was the most found in the groups, representing adhesive failures. The exception was group SEP, in which there was predominance of $\mathrm{ARI}=3$ (all the adhesive remnant on the enamel surface with the impression of the bracket base) (Table 3).

\section{SEM evaluation}

In group XT/Er:YAG, it was observed that the dental ablation performed by Er:YAG laser promoted the formation of craters and imperfections in the enamel, which were restricted to the ablated area, without the occurrence of fractures or cracks (Figure 1).

In groups XT and SEP, by means of SEM, no damage to the enamel surface was observed (Figure 2).

\section{Discussion}

The constant development of materials and techniques for dental bonding offers various clinical options for bonding orthodontic accessories. In this study, after simulation of 1 year of orthodontic treatment, the conventional and selfetching adhesive systems were found to show adequate bond strength; however, previous enamel treatment with Er:YAG laser (60 mJ, energy density $\left.19.24 \mathrm{~J} / \mathrm{cm}^{2}\right)$ reduced the bond strength of brackets bonded to enamel. Therefore, the null hypothesis of the study was rejected.

The bond strength of orthodontic brackets is usually verified 24 hours after they were bonded. ${ }^{16,18}$ However, not only the primary stability of orthodontic brackets but also their longevity are extremely important; nevertheless, most of the in vitro studies ${ }^{16,18}$ do not use artificial fatigue tests before evaluating the bond strength. It is proposed in the literature that thermal or thermal-mechanical cycling ${ }^{12}$ should be performed before the bond strength test, as was done in the present study.

After simulation of 1 year of orthodontic treatment, groups SEP (self-etching adhesive $10.3 \mathrm{MPa}$ ) and XT (total etch adhesive $\backslash 10.8 \mathrm{MPa}$ ) were statistically similar between them, ${ }^{1,12}$ and presented mean bond strength values corrobo-

Table 2 Statistical analysis of shear bond strength (MPa) of orthodontic adhesives

\begin{tabular}{lllllll}
\hline Groups & Adhesive systems & N & Mean (standard deviation) & Median (MPa) & $\begin{array}{l}\text { Minimum/maximum } \\
\mathbf{( M P a )}\end{array}$ & \begin{tabular}{l} 
25\%-75\% \\
\hline XT
\end{tabular} \\
& Transbond XT & 16 & $10.8(1.8)^{\mathrm{a}}$ & 10.4 & $8.19-14.57$ & $9.2-12.6$ \\
SEP & Transbond self-etching primer & 16 & $10.3(1.1)^{\mathrm{a}}$ & 10.3 & $8.62-12.75$ & $9.2-10.7$ \\
XT/ Er:YAG & Transbond XT + Er:YAG laser & 16 & $7.4(1.4)^{\mathrm{b}}$ & 7.1 & $6.06-11.87$ & $6.7-7.9$ \\
\hline
\end{tabular}

Note: ${ }^{a, b}$ Different letters indicate statistically significant differences, according to post hoc tests with Bonferroni correction ( $\left.p<0.005\right)$.

Abbreviations: Er:YAG, erbium: yttrium aluminum garnet laser; SEP, self-etching primer.

Table 3 Adhesive remnant scores of groups evaluated ( $\mathrm{n}[\%])$

\begin{tabular}{|c|c|c|c|c|c|c|}
\hline \multirow{2}{*}{$\begin{array}{l}\text { Group } \\
(n=16)\end{array}$} & \multicolumn{4}{|l|}{ ARI score } & \multirow{2}{*}{$\begin{array}{l}\text { Mean score } \\
\text { (median) }\end{array}$} & \multirow[t]{2}{*}{ Dunn* } \\
\hline & 0 & I & 2 & 3 & & \\
\hline $\mathrm{XT}$ & $10(62.5 \%)$ & $2(12.5 \%)$ & $3(18.8 \%)$ & I (6.3\%) & $0.69(0)$ & $A$ \\
\hline SEP & 2 (12.5\%) & $3(18.8 \%)$ & 5 (3I.3\%) & $6(37.5 \%)$ & $1.94(2)$ & $B$ \\
\hline XT/Er:YAG & I 4 (87.5\%) & $2(12.5 \%)$ & $0(0 \%)$ & $0(0 \%)$ & $0.13(0)$ & $A C$ \\
\hline
\end{tabular}

Note: *Different letters indicate statistically significant differences $(p<0.05)$.

Abbreviations: ARI, adhesive remnant index; Er:YAG, erbium: yttrium aluminum garnet laser; SEP, self-etching primer. 

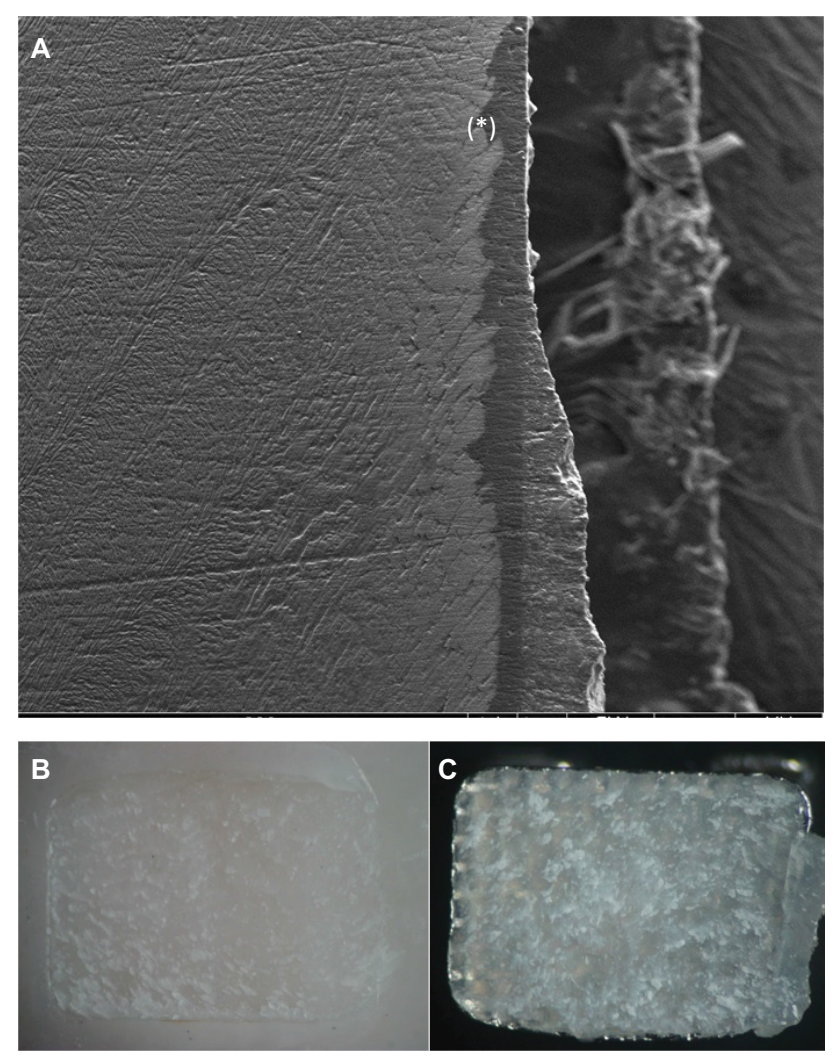

Figure I (A) Microimages of group XT/Er:YAG (500x) showing the damage to enamel caused by laser (*); (B) stereomicroscope images (20X) of the vestibular surface of tooth; and (C) bracket base.

Abbreviation: Er:YAG, erbium: yttrium aluminum garnet laser.
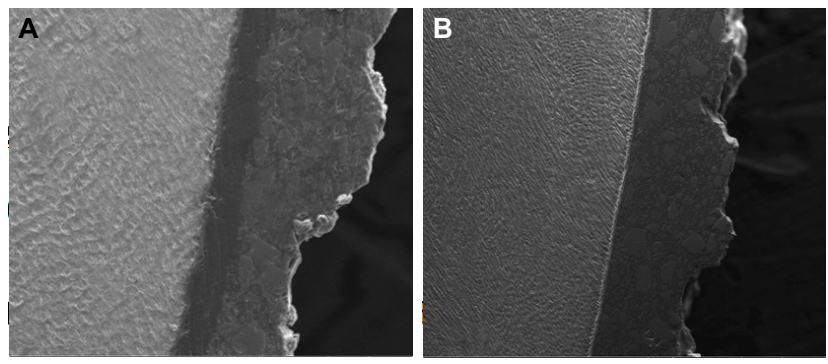

Figure 2 (A) Microimages of group XT (500x); (B) microimages of group SEP (500X). Abbreviation: SEP, self-etching primer.

rating the findings in the literature. ${ }^{1,6}$ The group treated with Er:YAG laser/XT (7.4 MPa) showed the lowest bond strength values, and these findings do not differ from those of studies that observed the bond strength 24 hours after bracket bonding to enamel previously treated with Er:YAG laser. ${ }^{6}$ However, it is reported in the literature ${ }^{19}$ that the variation between 5 and $50 \mathrm{MPa}$ indicates the ideal values of bond strength, contributing to the findings of the present study.

Previous studies ${ }^{14,20-22}$ have suggested the use of enamel conditioning with Er:YAG laser before orthodontic bracket bonding, with the intention of obtaining a tissue that was more resistant to acid dissolution around the brackets. However, it is difficult to compare the results, because various experimental conditions are used; while some combined the use of laser with acid, ${ }^{8,10}$ others used laser only to promote conditioning ${ }^{6,21,22}$ Enamel conditioning performed with laser parameters similar to those used for cavity preparations ${ }^{23}$ has also been suggested, ${ }^{11}$ and although adequate bond strength was obtained, severe and permanent damage to tooth enamel was generated. ${ }^{10}$

It has been reported that Er:YAG laser is a potentially adequate method for conditioning enamel, ${ }^{3,10,11}$ but it generates lower bond strength values when compared with the conventional acid etching technique. ${ }^{8,24}$

A low energy level of Er:YAG laser $(60 \mathrm{~mJ})$ was used in this study for previous conditioning of the enamel as described ${ }^{25,26}$ because it has been proposed that low energy levels $(60-80 \mathrm{~mJ})$ are capable of promoting demineralization without causing severe changes in enamel. ${ }^{25} \mathrm{~A}$ reduction of bond strength was observed, as has been pointed out in studies, ${ }^{25}$ in which different adhesive systems have been used, and the laser with the same parameters as those used in this study. However, even with the use of $150 \mathrm{~mJ}$ and an energy density similar to that used in our study $\left(19.1 \mathrm{~J} / \mathrm{cm}^{2}\right)$, the study by Contreras-Bulnes et al, ${ }^{6}$ who verified this parameter for conditioning enamel with the use of Er:YAG laser, also presented a significant reduction in bond strength, while other studies found adequate bond strength values after the use of these parameters. ${ }^{21,22}$

Conditioning with Er:YAG laser promotes lower tensile stress and demineralization when compared with phosphoric acid. ${ }^{8}$ The reduction in bond strength may also be related to the fact that the microhardness and modulus of elasticity of enamel are increased after irradiation with Er:YAG laser, when compared with enamel etched with phosphoric acid, which promotes a reduction in microhardness and modulus of elasticity. ${ }^{7}$ The application of Er:YAG laser has also been correlated with the presence of microfractures in the enamel subsurface and dentin, which are unfavorable to the bonding process. ${ }^{6,24}$ After treatment with phosphoric acid, a typical etching pattern is formed with mixed areas of removal of nucleus or peripheral portion of the core of the enamel prism. ${ }^{6}$ Er:YAG laser increases the free surface energy and roughness of enamel and dentin; however, it does not produce a desirable morphology for the bonding process. ${ }^{27}$

The bond strength of orthodontic brackets bonded to enamel previously treated with Er:YAG laser is still controversial, probably due to the difference in the methodologies used, and mainly in the variation of the energy and frequency parameters. ${ }^{10,28}$ 
The highest frequency of failures was verified at the adhesive/enamel interface. The exception was group SEP, whose bond failure occurred with greater frequency at the adhesive/bracket interface, corroborating the findings in the literature. ${ }^{1}$ The use of self-etching adhesive appears to favor this condition, which in practice may mean less risk of unpredictable damage to the enamel surface at the time of bracket removal by the professional, however, with the need to remove the adhesive remnant on the tooth surface after debonding.

According to the observations by SEM, the conventional and self-etching adhesives did not present damage to enamel after debonding. The Er:YAG laser promoted permanent irregularities in tooth enamel, even when using a low level of energy $(60 \mathrm{~mJ})$ and may generate an increase in enamel roughness and microfissures. ${ }^{6}$

In vitro studies have limitations because they do not reproduce the oral environment in all its complexity. However, laboratory studies are important because preliminary evaluations are necessary to indicate the feasibility of the clinical application of dental techniques and materials.

Therefore, in vitro studies require further investigation to elucidate the influence of these resinous materials and the behavior of the Er:YAG laser (associated to different irradiation parameters and/or subjected to erosive cycles) on the surface of the dental enamel, contributing to the improvement of longevity of the adhesive techniques of brackets and their clinical applicability.

\section{Conclusion}

Within the limitations of this study, after simulation of 1 year of orthodontic treatment, by means of thermal-mechanical cycling, it was possible to observe that:

1. The conventional (XT) and self-etching (SEP) adhesive systems presented similar mean bond strength values between them.

2. The previous application of Er:YAG laser, within the parameters used, associated with the use of the conventional adhesive system (XT) promoted the lowest bond strength values.

3. With exception of the group treated with self-etching adhesive, a large portion of the failures occurred at the enamel/adhesive interface.

\section{Acknowledgment}

The authors are grateful to the assistance granted by FAPEMA - Foundation of Maranhão Research.

\section{Disclosure}

The authors report no conflicts of interest in this work.

\section{References}

1. Buyukyilmaz T, Usumez S, Karaman AI. Effect of self-etching primers on bond strength - are they reliable? Angle Orthod. 2003;73(1):64-70.

2. Romano FL, Tavares SW, Nouer DF, Consani S, Borges de Araújo Magnani MB. Shear bond strength of metallic orthodontic brackets bonded to enamel prepared with self-etching primer. Angle Orthod. 2005;75(5):849-853.

3. Basaran G, Ozer T, Berk N, Hamamci O. Etching enamel for orthodontics with an erbium, chromium:yttrium- scandium-gallium-garnet laser system. Angle Orthod. 2007;77(1):117-123.

4. Ahrari F, Poosti M, Motahari P. Enamel resistance to demineralization following Er:YAG laser etching for bonding orthodontic brackets. Dent Res J (Isfahan). 2012;9(4):472-477.

5. Karandish M. The efficiency of laser application on the enamel surface: a systematic review. J Lasers Med Sci. 2014;5(3):108-114.

6. Contreras-Bulnes R, Scougall-Vilchis RJ, Rodríguez-Vilchis LE, Centeno-Pedraza C, Olea-Mejía OF, Alcántara-Galena Mdel C. Evaluation of self-etching adhesive and Er:YAG laser conditioning on the shear bond strength of orthodontic brackets. ScientificWorldJournal. 2013;2013:719182.

7. Alavi S, Birang R, Hajizadeh F, Banimostafaee H. Effect of bracket bonding with Er: YAG laser on nanomechanical properties of enamel. Dent Res J (Isfahan). 2014;11(1):49-55.

8. Lasmar MF, Reher VG, Lalloo R, Reher P. Enamel demineralization and bracket bond strength when etching with acid and/or Er:YAG laser. Aust Dent J. 2012;57(2):190-195.

9. Fornaini C, Brulat N, Milia G, Rockl A, Rocca JP. The use of subablative Er:YAG laser irradiation in prevention of dental caries during orthodontic treatment. Laser Ther. 2014;23(3):173-181.

10. Türköz C, Ulusoy C. Evaluation of different enamel conditioning techniques for orthodontic bonding. Korean J Orthod. 2012;42(1):32-38.

11. Kim JH, Kwon OW, Kim HI, Kwon YH. Effectiveness of an Er:YAG laser in etching the enamel surface for orthodontic bracket retention. Dent Mater J. 2005;24(4):596-602.

12. Schaneveldt S, Foley TF. Bond strength comparison of moistureinsensitive primers. Am J Orthod Dentofacial Orthop. 2002;122(3): 267-273.

13. Krifka S, Börzsönyi A, Koch A, Hiller KA, Schmalz G, Friedl KH. Bond strength of adhesive systems to dentin and enamel-human vs. bovine primary teeth in vitro. Dent Mater. 2008;24(7):888-894.

14. Hossain M, Nakamura Y, Kimura Y, Yamada Y, Ito M, Matsumoto K. Caries-preventive effect of Er:YAG laser irradiation with or without water mist. J Clin Laser Med Surg. 2000;18(2):61-65.

15. Bezerra GL, Torres CR, Tonetto MR, et al. Shear bond strength of orthodontic brackets fixed with remineralizing adhesive systems after simulating one year of orthodontic treatment. ScientificWorldJournal. 2015;2015:903451.

16. Scougali Vilchis RJ, Yamamoto S, Kitai N, Yamamoto K. Shear bond strength of orthodontic brackets bond with different self-etching adhesives. Am J Orthod Dentofacial Orthop. 2009;136(3):425-430.

17. Artun J, Bergland S. Clinical trials with crystal growth conditioning as an alternative to acid-etch enamel pretreatment. Am J Orthod. 1984;85(4):333-340.

18. Reicheneder CA, Gedrange T, Lange A, Baumert U, Proff P. Shear and tensile bond strength comparison of various contemporary orthodontic adhesive systems: an in-vitro study. Am J Orthod Dentofacial Orthop. 2009; 135(4):422.e1-e6.

19. Scribante A, Contreras-Bulnes R, Montasser MA, Vallittu PK. Orthodontics: bracket materials, adhesives systems, and their bond strength. Biomed Res Int. 2016;2016:1329814.

20. Liu Y, Hsu CY. Laser-induced compositional changes on enamel: a FT-Raman study. J Dent. 2007;35(3):226-230. 
21. Raji SH, Birang R, Majdzade F, Ghorbanipour R. Evaluation of shear bond strength of orthodontic brackets bonded with Er-YAG laser etching. Dent Res J (Isfahan). 2012;9(3):288-293.

22. Hosseini MH, Namvar F, Chalipa J, et al. Comparison of shear bond strength of orthodontic brackets bonded to enamel prepared by Er:YAG laser and conventional acid-etching. J Dent (Tehran). 2012;9(1): 20-26.

23. Armengol V, Jean A, Rohanizadeh R, Hamel H. Scanning electron microscopic analysis of diseased and healthy dental hard tissues after Er:YAG laser irradiation: in vitro study. J Endod. 1999;25(8): 543-546.

24. Martínez-Insua A, Da Silva Dominguez L, Rivera FG, Santana-Penín UA. Differences in bonding to acid-etched or Er:YAG-laser-treated enamel and dentin surfaces. J Prosthet Dent. 2000;84(3):280-288.
25. Cecchini RC, Zezell DM, de Oliveira E, de Freitas PM, Eduardo Cde P. Effect of Er:YAG laser on enamel acid resistance: morphological and atomic spectrometry analysis. Lasers Surg Med. 2005;37(5):366-372.

26. Pucci CR, de Oliveira RS, Caneppele TM, Torres CR, Borges AB, Tay FR. Effects of surface treatment, hydration and application method on the bond strength of a silorane adhesive and resin system to dentine. J Dent. 2013;41(3):278-286.

27. Armengol V, Laboux O, Weiss P, Jean A, Hamel H. Effects of Er:YAG and $\mathrm{Nd}$ :YAP laser irradiation on the surface roughness and free surface energy of enamel and dentin: an in vitro study. Oper Dent. 2003; 28(1):67-74.

28. Sağır S, Usumez A, Ademci E, Usumez S. Effect of enamel laser irradiation at different pulse settings on shear bond strength of orthodontic brackets. Angle Orthod. 2013;83(6):973-980.
Clinical, Cosmetic and Investigational Dentistry

\section{Publish your work in this journal}

Clinical, Cosmetic and Investigational Dentistry is an international, peer-reviewed, open access, online journal focusing on the latest clinical and experimental research in dentistry with specific emphasis on cosmetic interventions. Innovative developments in dental materials, techniques and devices that improve outcomes and patient satisfac-

\section{Dovepress}

tion and preference will be highlighted. The manuscript management system is completely online and includes a very quick and fair peerreview system, which is all easy to use. Visit http://www.dovepress. com/testimonials.php to read real quotes from published authors. 